\title{
Data integrity issues: catalyst for a more robust approach to research on perioperative oxygen therapy?
}

\author{
Alex H. Oldman ${ }^{1 *}$ D, Andrew F. Cumpstey ${ }^{1,2}$, Daniel S. Martin ${ }^{3}$ and Michael P. W. Grocott ${ }^{1,2}$
}

Keywords: Oxygen, Perioperative care, Surgery, Anaesthetics, Hyperoxia

In February 2019, data integrity from 38 published randomised controlled trials in surgical patients conducted by an Italian surgical research group was called into question (Buranyi and Devlin 2019). Using the Carlisle method, Myles, Carlisle and Scarr identified evidence of compromised data in 38 out of 40 published articles from Mario Schietroma's research group spanning from years 1993 to 2016 (Myles et al. 2019). In their analysis, they meta-analysed all published patient characteristic data, identifying poorly distributed participant characteristics, incorrect ' $p$ ' values and overly consistent results. There was enough evidence from this analysis to recommend an inquiry into the group's work, and their published outputs are likely to have been misleading researchers within the field of perioperative medicine for some years (Myles et al. 2019). Such alleged misconduct is not only damaging to the scientific community and to perioperative research, but may also have substantial global consequences for patient safety through the impact of flawed research on doctors' prescribing habits. Two of Schietroma's papers had been referenced by the World Health Organisation's (WHO) 'Global guidelines for the prevention of surgical site infection' and included in their meta-analysis on perioperative oxygenation published initially in 2016. In this, they made a strong recommendation (subsequently downgraded to 'conditional' in 2018 ) to provide $80 \%$ oxygen to all intubated patients undergoing surgery requiring general anaesthesia and intubation (Global guidelines for the prevention of surgical site infection 2018). To put this value into perspective,

\footnotetext{
* Correspondence: alex.oldman@gmail.com

${ }^{1}$ Critical Care Research Group, Southampton National Institute of Health Research, Biomedical Research Centre, University Hospital Southampton, Southampton, UK

Full list of author information is available at the end of the article
}

this is a recommendation to give surgical patients almost four times more inspired oxygen than is physiologically normal under healthy conditions.

The field of perioperative oxygen research is perplexing even for the well initiated. There seems to be a real contradiction between prescribing recommendations and trial evidence. Early studies reporting the beneficial effects of high-dose perioperative oxygen therapy in reducing surgical site infections and postoperative complications provided the majority of evidence for the 2016 WHO guidelines (Greif et al. 2000; Belda et al. 2005; Myles et al. 2007). These results, however, were not supported by data from a much larger trial, which showed no impact on surgical site infections from higher inspired oxygen concentrations (Meyhoff et al. 2009). Additionally, a Cochrane systematic review and metaanalysis published in 2015 concluded that there was insufficient evidence to support routinely giving anaesthetised patients more than $60 \%$ oxygen intraoperatively (Wetterslev et al. 2015). The most up-to-date systematic reviews and meta-analyses support the modified WHO recommendation, suggesting that there is "little evidence on safety-related issues" and "no definite signal of harm" with administering an $80 \%$ oxygen in adult patients undergoing general anaesthesia (de Jonge et al. 2019; Mattishent et al. 2019). These reviews support the fact that there remains little evidence for definite benefit of high perioperative fractions of oxygen and suggest that evidence for giving $80 \%$ oxygen in order to reduce the risk of surgical site infections has substantively changed, calling for the international recommendations to be urgently reconsidered (de Jonge et al. 2019).

Importantly, clinical outcome studies in patients in other contexts have provided evidence of harm from highdose oxygen. Notably, the Improving Oxygen Therapy in 
Acute-illness (IOTA) systematic review, published in the Lancet in 2018, reported that liberal use of oxygen to maintain saturations above $96 \%$ was associated with increased in-hospital and 30-day mortality in acutely unwell patients (Chu et al. 2018). Whilst this study explicitly excluded patients undergoing elective surgery, observation of a harm signal across such a large and broad group of acutely unwell patients should be cause for concern for those advocating high-dose oxygen therapy in patients undergoing surgery. An additional concern that has more recently emerged from the literature is the potential adverse effect of high-dose perioperative oxygen therapy on longer-term outcomes. Such outcomes have also been studied across three follow-up analyses from the Danish PROXI trial (Fonnes et al. 2016; Meyhoff et al. 2012; Meyhoff et al. 2014), a randomised controlled trial of 1386 patients undergoing acute or elective laparotomy and given either $30 \%$ or $80 \%$ oxygen during and after surgery (Meyhoff et al. 2009). A 2-year post-hoc analysis of the PROXI data revealed that the incidence of acute MI was over twice as frequent in those patients given $80 \%$ oxygen in comparison to 30\% (HR 2.86 (95\% CI 1.10-7.44), $p=$ 0.03) (Fonnes et al. 2016). When controlling for broader incidence of cardiac complications, researchers found statistical significance with higher fractions of oxygen and 'any heart disease or death' (HR 1.24 95\% CI 1.06-1.45, $p$ $=<0.01)$. An additional 2-year follow-up study demonstrated an increase in long-term mortality in cancer patients who received $80 \%$ oxygen (HR 1.45; $95 \%$ CI 1.10 to 1.90; $p=0.009$ ) (Meyhoff et al. 2012), and, remarkably, a 4-year post-hoc study showed an overall reduction in cancer-free survival time across all trial patients receiving $80 \%$ oxygen (HR $1.19 ; 95 \%$ CI 1.01 to $1.42 ; p=0.04$ ) (Meyhoff et al. 2014). It is worth noting that these posthoc analyses were not included in the WHO 2016 guidelines for SSI prevention. The PROXI trial was originally powered to detect a reduction in surgical site infections only, and therefore, these post-hoc analyses should still be treated with some caution; once an experimental group has been associated with one adverse outcome, it is not surprising that there might also be other adverse associations too. Despite this, their findings present an important new avenue for oxygen research and a starting point for hypotheses to be generated.

Paul Bert and James Lorrain Smith first described the detrimental effects of hyperbaric oxygen on the central nervous system and pulmonary tissues in the late nineteenth century (Martin and Grocott 2013). The spotlight has now moved to highlight the toxic effects of normobaric hyperoxia, which has profound effects on the cardiovascular system; causing increased systemic vascular resistance, reduced cardiac output, and coronary vasoconstriction, all of which limits coronary perfusion (Martin and Grocott 2013; Lumb and Walton 2012). Pulmonary tissue is also particularly susceptible to oxygen-induced injury, with dose-dependent pulmonary oedema, alveolar inflammation and atelectasis worsening ventilation/perfusion mismatching (Martin and Grocott 2013; Lumb and Walton 2012). Other organs, including the brain and kidneys are also susceptible to 'hyperoxic injury', and worse outcomes with hyperoxia are being reported in an increasing number of clinical scenarios; high-flow oxygen is no longer indicated in the management of acute coronary syndrome (particularly myocardial infarction) or neonatal resuscitation, despite previously being considered essential initial management in both situations (Cabello et al. 2016; Tan et al. 2005). Equally, clinical trials have shown increased harm with liberal oxygen therapy in stroke victims, critical illness and following cardiac arrest (Rincon et al. 2014; Diamani et al. 2014; Killgannon et al. 2010).

On a cellular level, these pathologies are likely mediated by reactive oxygen species (ROS) - unstable free radicals in part generated as by-products of oxidative phosphorylation in the mitochondrial electron transport chain (Helmerhost et al. 2015). ROS have many essential biological functions including oxygen sensing, cellular signalling and immune response modulation. However, excessive ROS build-up leads to oxidative stress, resulting in cellular damage through direct reactions with lipid membranes, DNA and proteins, inducing apoptosis and necrosis (Helmerhost et al. 2015; Auten and Davis 2009; Dias-Freitas et al. 2016). Hyperoxia appears to fuel this pro-inflammatory state, triggering cytokine cascades, neutrophil activation and worsening tissue oedema (Martin and Grocott 2013; Helmerhost et al. 2015). There is now an urgent need to delineate and quantify cellular responses to changes in oxygen availability in surgical patients and to determine how inspired oxygen fractions affect tissue inflammation and oxidative stress perioperatively.

The dissonance between oxygen guidelines and evidence from both clinical outcomes and mechanistic research is reflected in prescribing practices amongst UK anaesthetists. A recent multi-site evaluation of practice demonstrated that intraoperative oxygen administration by anaesthetists varied widely from 25 to $100 \%$, with no obvious down-titration of oxygen in response to sustained supra-normal blood oxygen levels (Morkane et al. 2018). These findings were also supported by an observational cohort study of emergency department (ED) practice suggesting that clinicians may target hyperoxia in this context. The authors reported that acute hyper-oxygenation via an endotracheal tube in the ED was an independent predictor of hospital mortality (adjusted OR 1.95; 95\% CI 1.34 to $2.85 ; p=<0.001$ ) (Page et al. 2018).

Despite a substantial number of high-quality cohort studies and clinical trials, there remains a paucity of high-quality evidence to demonstrate the physiological 
effects oxygen has during the perioperative period, particularly at a cellular level. Consequently, anaesthetic guidelines and recommendations for perioperative oxygen therapy currently remain poorly grounded in scientific understanding. We would argue that the revelations of the Myles, Carlisle and Scarr's manuscript on the Schietroma papers should be used to provide perioperative physicians and anaesthetists with a fresh opportunity to discuss oxygen prescribing practices and promote high-quality research in order to clearly define safe and effective care in this area. Oxygen therapy remains the most common component of general anaesthesia, yet as a community, we appear to have little idea how much oxygen we should be prescribing for our patients and what pathophysiological mechanisms we should be basing this prescription on. This somewhat embarrassing paradox at the heart of anaesthetic practice requires urgent resolution if we are to reduce harm and improve the lives of those we care for during and after surgery.

\section{Acknowledgements}

N/A

\section{Authors' contributions}

$\mathrm{AHO}$ contributed to the editorial conception, and writing and editing of the manuscript. AC, DSM and MPWG helped in writing and editing the manuscript. All authors read and approved the final manuscript.

\section{Funding}

AC is currently funded through the NIHR's Biomedical Research Centre (BRC) at the University of Southampton as a Clinical Research Fellow. MG is currently funded through the NIHR Southampton Biomedical Research Centre and the NIHR Senior Investigator Scheme.

\section{Availability of data and materials}

N/A

\section{Ethics approval and consent to participate}

N/A

\section{Consent for publication}

N/A

\section{Competing interests}

AHO has no competing interests. AC has received funding through the NIHR as an Academic Clinical Fellow. DSM has received consultancy fees from Siemens Healthcare and Masimo and lecture honoraria from Edwards Lifesciences and Deltex Medical. He is also a Director of Oxygen Control Ltd. MPWG serves on the medical advisory board of Sphere Medical Ltd. and is a director of Oxygen Control Systems Ltd. He has received honoraria for speaking for and/or travel expenses from BOC Medical (Linde Group), Edwards Lifesciences and Cortex GmBH. MPWG leads the Xtreme Everest Oxygen Research Consortium and the Fit-4-Surgery research collaboration. Some of this work was undertaken at the University Southampton NHS Foundation Trust-University of Southampton NIHR Biomedical Research Centre. MPWG serves as the UK NIHR CRN national specialty group lead for Anaesthesia Perioperative Medicine and Pain and is an elected council member of the Royal College of Anaesthetists and president of the Critical Care Medicine Section of the Royal Society of Medicine.

\section{Author details}

'Critical Care Research Group, Southampton National Institute of Health Research, Biomedical Research Centre, University Hospital Southampton, Southampton, UK. ${ }^{2}$ Integrative Physiology and Critical Illness Group, Clinical and Experimental Sciences, Faculty of Medicine, University of Southampton,
Southampton, UK. ${ }^{3}$ Division of Surgery and Interventional Science (University College London) and Royal Free Perioperative Research Group, Department of Anaesthesia, Royal Free Hospital, 3rd Floor, Pond Street, London NW3 2QG, UK.

Received: 1 May 2019 Accepted: 26 June 2019

Published online: 04 July 2019

\section{References}

Auten R, Davis JM. Oxygen toxicity and reactive oxygen species: the devil is in the details. PediatrRes. 2009:66:121-7.

Belda FJ, Aguilera L, Garcia de la Asuncion J. et.al. Supplemental perioperative oxygen and the risk of surgical wound infection: a randomized controlled trial. JAMA. 2005;294(16):2035-42.

Buranyi S. and Devlin H. Anaesthetists say patients at risk after flawed oxygen guidelines. The Guardian. 2019. Available at:https://www.theguardian.com/ society/2019/feb/18/anaesthetists-say-patients-at-risk-after-flawed-oxygenguidelines (Accessed 23 June 2019).

Cabello JB, Burls A, Emparanza JI, Bayliss SE, Quinn T. Oxygen therapy for acute myocardial infarction. Cochrane Database Syst Rev. 2016;12:CD007160. https://doi.org/10.1002/14651858.CD007160.pub4.

Chu DK, Kim LH, Young PJ, et al. Mortality and morbidity in acutely ill adults treated with liberal versus conservative oxygen therapy (IOTA): a systematic review and meta-analysis. Lancet. 2018:391:1693-705.

de Jonge S, Egger M, Latif A, et al. Effectiveness of $80 \%$ vs $30-35 \%$ fraction of inspired oxygen in patients undergoing surgery: an updated systematic review and meta-analysis. BJA. 2019;122(3):325-34.

Diamani E, Adrario E, Girardis M, et al. Arterial hyperoxia and mortality in critically ill patients: as systematic review and meta-analysis. Crit Care. 2014;18:711.

Dias-Freitas F, Metelo-Coimbra C, Roncon-Alberquerque R Jr. Molecular mechanisms underlying hyperoxia acute lung injury. Respir Med. 2016; 119:23-8.

Fonnes S, Gogenur I, Sondergaard ES, et al. Perioperative hyperoxia - Long-term impact on cardiovascular complications after abdominal surgery, a post hoc analysis of the PROXI trial. Int J Cardiol. 2016:215:238-43.

Global guidelines for the prevention of surgical site infection, second edition Geneva: World Health Organization; 2018. Licence: CC BY-NC-SA 3.0 IGO.

Greif R, Akca O, Horn EP, et al. Supplemental perioperative oxygen to reduce the incidence of surgical-wound infection. N Engl J Med. 2000;342(3):161-7.

Helmerhost HJF, Shultz MJ, van der Voort PHJ. et.al. Bench-to-bedside review: the effects of hyperoxia during critical illness. Critical Care. 2015;19:248.

Killgannon JH, Jones AE, Shapiro NI, et al. Association Between Arterial Hyperoxia Following Resuscitation From Cardiac Arrest and In-Hospital Mortality. JAMA. 2010;303(21):2165-71.

Lumb AB, Walton L. Perioperative Oxygen Toxicity. Anesthesiology Clinics. 2012; 30(4):591-605.

Martin DS, Grocott MPW. Oxygen Therapy in Critical IIIness. Crit Care Med. 2013; 41(2):423-32

Mattishent K, Thavarajah M, Sinha A, et al. Safety of $80 \%$ vs 30-35\% fraction of inspired oxygen in patients undergoing surgery: a systematic review and meta-analysis. BJA. 2019;122(3):311-24.

Meyhoff CS, Jorgensen LN, Wetterslev J, Christensen KB, Rasmussen LS. Increased long-term mortality after a high perioperative inspiratory oxygen fraction during abdominal surgery: follow-up of a randomized clinical trial. Anesth Analg. 2012;115:849-54.

Meyhoff CS, Jorgensen LN, Wetterslev J, et al. Risk of new and recurrent cancer after a high perioperative inspired oxygen fraction during abdominal surgery. BJA. 2014;113(Suppl1):174-i81.

Meyhoff CS, Wetterslev J, Jorgensen LN, et al. Effect of high perioperative oxygen fraction on surgical site infection and pulmonary complications after abdominal surgery: the PROXI randomized clinical trial. JAMA. 2009: 302(14):1543-50

Morkane CM, McKenna H, Cumpstey A, Oldman AH, et al. Intraoperative oxygenation in adult patients undergoing surgery (iOPS): a retrospective observational study across 29 UK hospitals. Periop Med. 2018;7:17.

Myles PS, Carlisle JB, Scarr B. Evidence for compromised data integrity in studies of liberal peri-operative inspired oxygen. Anaesthesia. 2019;74(5):573-84.

Myles PS, Leslie K, Chan MT. Avoidance of nitrous oxide for patients undergoing major surgery: a randomized controlled trial. Anesthesiology. 2007;107(2):221-31. 
Page D, Ablordeppey E, Wessman BT, et al. Emergency department hyperoxia is associated with increased mortality in mechanically ventilated patients: a cohort study. Crit Care. 2018;22:9.

Rincon F, Kang J, Maltenfort M, et al. Association between hyperoxia and mortality after stroke: a multicenter cohort study. Crit Care Med. 2014; 42(2):387-96.

Tan A, Schulze AA, O'Donnell CPF, Davis PG. Air versus oxygen for resuscitation of infants at birth. Cochrane Database Syst Rev. 2005;2:CD002273. https://doi. org/10.1002/14651858.CD002273.pub3.

Wetterslev J, Meyhoff CS, Jørgensen LN, Gluud C, Lindschou J, Rasmussen LS. The effects of high perioperative inspiratory oxygen fraction for adult surgical patients. Cochrane Database Syst Rev. 2015;6:6.

\section{Publisher's Note}

Springer Nature remains neutral with regard to jurisdictional claims in published maps and institutional affiliations.

Ready to submit your research? Choose BMC and benefit from:

- fast, convenient online submission

- thorough peer review by experienced researchers in your field

- rapid publication on acceptance

- support for research data, including large and complex data types

- gold Open Access which fosters wider collaboration and increased citations

- maximum visibility for your research: over $100 \mathrm{M}$ website views per year

At BMC, research is always in progress.

Learn more biomedcentral.com/submissions 